\title{
The Human Right to Water and Sanitation: Using Natural Language Processing to Uncover Patterns in Academic Publishing
}

\author{
Christopher Michael Faulkner ${ }^{1, *(\mathbb{D})}$, Joshua Earl Lambert ${ }^{2}$, Bruce M. Wilson ${ }^{2,3} \mathbb{D}^{\mathrm{D}}$ and Matthew Steven Faulkner ${ }^{4}$ \\ 1 Department of National Security Affairs, U.S. Naval War College, Newport, RI 02841, USA \\ 2 School of Politics, Security, and International Affairs, University of Central Florida, Orlando, FL 32816, USA; \\ joshua.lambert@ucf.edu (J.E.L.); bruce.wilson@ucf.edu (B.M.W.) \\ 3 Chr. Michelsen Institute, P.O. Box 6033, N-5892 Bergen, Norway \\ 4 Lucas College and Graduate School of Business, San José State University, San José, CA 95112, USA; \\ matthew.faulkner@sjsu.edu \\ * Correspondence: christopher.faulkner@usnwc.edu
}

Citation: Faulkner, C.M.; Lambert, J.E.; Wilson, B.M.; Faulkner, M.S. The Human Right to Water and Sanitation Using Natural Language Processing to Uncover Patterns in Academic Publishing. Water 2021, 13, 3501. https://doi.org/10.3390/w13243501

Academic Editor: Guy Howard

Received: 10 November 2021 Accepted: 6 December 2021

Published: 8 December 2021

Publisher's Note: MDPI stays neutral with regard to jurisdictional claims in published maps and institutional affiliations.

Copyright: (c) 2021 by the authors. Licensee MDPI, Basel, Switzerland. This article is an open access article distributed under the terms and conditions of the Creative Commons Attribution (CC BY) license (https:/ / creativecommons.org/licenses/by/ $4.0 /)$.

\begin{abstract}
After years of advocacy and international negotiation, the General Assembly of the United Nations voted to officially recognize a stand-alone human right to water and sanitation on 28 July 2010. Since, academic scholarship has continued to grow in an effort to understand the implications of the codification of this human right. Yet, with this growth, it has become impractical if not impossible for scholars to keep up with the advancement of academic knowledge or to make sense of it in a systematic way. In short, to date, we know very little about the trends in the literature as they have unfolded over the past thirty years and the topics to which scholars have devoted significant attention within the broader field, particularly over time. This is an important area of inquiry, as developing a comprehensive understanding of where prior literature has focused and where it appears to be going offers scholars an opportunity to identify areas in need of refinement and/or increased attention. Given the practicalities of reading thousands of research papers each year, this project utilizes natural language processing (NLP) to identify topics and trends in academic literature on the human right to water and sanitation (HRtWS). NLP provides the opportunity to digest large quantities of text data through machine learning, culminating with descriptive information on trends and topics in the field since 1990. The results of this exercise show that the research related to the human right to water and sanitation has grown exponentially, particularly over the last decade, illustrates the multidisciplinary nature of the literature, and demonstrates the diversity of topics in the field.
\end{abstract}

Keywords: water; sanitation; human rights; human right to water and sanitation; HRtWS; natural language processing; machine learning; text analysis

\section{Introduction}

Making sense of the expansive literature on the human right to water and sanitation (HRtWS) is understandably difficult. The multi- and interdisciplinary nature of the research on this topic, intersecting with academic fields such as law, political science, health, engineering, sociology, environmental studies, and geography, to name a few, can make it challenging for scholars to "keep up" with the diverse array of trends and findings in extant literature. In fact, the number of papers investigating topics related to the human right to water and sanitation has grown exponentially, with nearly 75 percent of articles since 1990 being published within the past decade (2010-2020).

This manuscript seeks to synthesize the last thirty years of research on the human right to water and sanitation by utilizing methodological advances in natural language processing (NLP) and machine learning. These strategies afford researchers an opportunity to "make sense" of large amounts of data that individual researchers may have difficulties 
both identifying and unpacking. Moreover, this strategy is particularly attractive as it widens the lens-allowing us to truly explore the field's multidisciplinary nature as well as the interdisciplinary approaches within academic scholarship on these topics. Put differently, while individual researchers may be able to engage with a wide array of academic scholarship there are undoubtedly practicalities and shortcuts that she/he/they may adopt in an effort to be as efficient as possible. Such strategies might include focusing on specific journals that align with the researcher's respective field(s) of inquiry or filtering for literature that has been published by well-established and highly cited researchers. These efforts certainly make sense given time and human constraints that make digesting large quantities of research difficult, but they are inherently limited and can result in the unintentional neglect of important studies and insights in the field or missed opportunities to engage with cross-cutting literature. We believe that this is an important gap, one which our study aims to fill.

Our approach helps overcome these practical limitations. Natural language processing and machine learning provide a systematic way to extract and analyze large quantities of text to identify and uncover patterns across publications [1]. Edgcomb and Zima [2] for instance, illustrate how such approaches allow researchers an opportunity to synthesize available literature to make practical improvements in the quality of mental health services and care. Similarly, Fisher et al. [3] use these strategies to explore the state of the literature in the fields of accounting, auditing, and finance, providing both a repository of knowledge as well as a path for future research. Such efforts are visible across a diverse array of academic disciplines, but to the best of knowledge, have not been undertaken in the field of human rights-and specifically concerning the human right to water and sanitation. For example, while scholars have used text and data mining tools, natural language processing, and machine learning strategies to help predict legal decisions at the European Court of Human Rights [4], to explore patterns in ways in which human rights are reported on over time and space [5], or to understand water disputes at the subnational level [6], the field is devoid of studies that use these tools to synthesize the literature in a way that offers a concrete digest and understanding of where the literature has been and where it is going.

From our perspective, the present study is not only interesting but imperative so that scholars have a more complete sense of how academic scholarship has evolved over the past three decades. Our topic modeling approach is also useful in the sense that it can help researchers (and policymakers) explore potential gaps in the literature on the HRtWS. Moreover, identifying trends in the literature in terms of temporal patterns of when and which topics are being addressed can further improve our understanding of how research changes (or not) in the aftermath of significant policy changes and/or advancements in human rights such as the United Nations' official codification of the human right to water and sanitation. Taken together, our project enables more rigorous thinking about the ways scholars organize their research and gives researchers and practitioners a foundation from which they can advance their own research efforts on the human right to water and sanitation.

The remainder of this paper is structured as follows. The Section 1 presents a brief discussion on the evolution of the human right to water and related literature. Section 2 provides an overview of the data and methods utilized in our empirical strategy. Here, we focus our attention on our data collection procedures and the logic of natural language processing and machine learning as cutting-edge tools that enhance our opportunity to more fully engage with the large quantity of research to date. Sections 3 and 4 report the results of our empirical strategy presenting details about temporal trends in the literature including the specific journals in which papers on the human right to water and sanitation are most frequently published and the topics that appear to be most prevalent within these articles. We conclude with a discussion of the results, summarizing the general patterns observed and the implications for future research. 


\section{The Human Right to Water and Sanitation}

Although water is an essential component for all human life, it was not included as part of the landmark United Nations Universal Declaration of Human Rights in 1948. Rather it took more than 60 years before the United Nations General Assembly finally recognized access to sufficient, affordable, accessible water and sanitation as a standalone right "essential for the full enjoyment of life and all human Rights" - United Nations Resolution 64/292 [7]. The glacial movement to create human rights to water and sanitation took many decades and the efforts of diplomats, activists, and academics pushed in many different international arenas. The first major step toward recognizing a human right to water and sanitation came when a human right to water was identified and derived from language contained in the 1966 International Covenant on Economic, Social, and Cultural Rights (ICESCR). In the following decades, the 1979 Convention on the Elimination of All Forms of Discrimination Against Women (CEDAW), and the 1989 Convention on the Rights of the Child (CRC) both explicitly recognized the Human Right to Water and Sanitation.

In 2002, General Comment 15 of the United Nations Committee on Economic, Social and Cultural Rights (CESCR) clearly stated that the HRtWS was explicitly and "inextricably" linked to existing human rights including the right to an adequate standard of living extending to food and housing (Article 11) and the human right to the highest attainable standard of health (Article 12) [8]. Furthermore, General Comment 15 encouraged states to "domesticate" the human right to water to encourage policymakers to improve the provision of access to clean, affordable drinking water [9]. This movement towards creating standalone human rights to water and sanitation culminated in the UN declaration of water and sanitation as a human right in 2010. This right created a wave of optimism that swept through the international community with many scholars and practitioners expecting significant, lasting benefits on public health and standards of living as a result $[10,11]$.

In tandem with these international developments that gradually recognized the HRtWS was a vibrant, expansive academic and grey multidisciplinary literature that used various lenses to examine the potential value of elevating water and sanitation to standalone human rights $[12,13]$. Several studies examined various relationships between water and sanitation rights and other issues such as health. Studies have demonstrated the link between a lack of access to safe, affordable, and clean drinking water and sanitation on the one hand and increased incidence of potentially fatal diseases such as cholera, typhoid dysentery, and diarrhea resulting in diminished aggregate health indicators and increasing incidents of childhood development problems and early death [14]. Other research focused on the economic problems resulting from a lack of access to clean water and sanitation [15] or the debate over the nature of water: is it a public good, or an economic commodity to be privatized and sold at its market price? In response to many countries' adoption of neoliberal economic policies that included the privatization of previously state-owned water providers, many scholars focused on water privatization and its highly publicized and disastrous impacts on access to water for many marginalized people around the world [16]. In one such case in 2000, the "Cochabamba Water War" in Bolivia illuminated the negative impact of water privatization, part of the World Bank neoliberal economic packages, on access to water of the most marginalized people in the world [17]. State violence against protestors in Bolivia resulted in six people being killed [18] and consequently the reversal of the privatization measure. These anti-privatization events in Bolivia became a key component of the movement to make water a human right at the international level $[19,20]$.

At the same time, many have suggested that while the global consensus of a human right to water and sanitation is a beneficial tool to enhance access to water and sanitation; those rights are not self-acting. Rather, the multidimensional nature of water and sanitation present numerous difficulties in translating rights "obligations" into action and reality [21-23]. Some scholars have been skeptical of the potential of human rights approaches to policy issues in general [24], while others are more sanguine about their effectiveness [25]. In terms of the impact of the human right to water, some have argued 
that it has been limited to affecting policies that resulted in mere technical adjustments, rather fundamental changes that resolve the issue of access $[26,27]$.

With the creation of the HRtWS, scholars began to examine related but divergent aspects of water and sanitation including the relationship between water and health [28], water and food; water scarcity and conflict between agriculture, industry, and human consumption; water and corruption [29]; water and the environment; indigenous peoples' rights to prior consent; water and development including mega projects such as dam construction [30]; and environmental rights and the legal rights of rivers [31]; infrastructure [32-34]. Other studies pivot in a different direction to focus on hydrology, water treatment, water management [35] or on the politics and policy of water and sanitation access $[27,36]$. Because water is so central to all areas of life, economy, and environment, the academic literature on water and sanitation rights has taken many different directions. The catalyst of the creation of the HRtWS to water and sanitation can be seen as a tipping point rather than the end of the process. The HRtWS requires significant political will and major policy changes including, increased planning, investment in infrastructure, and engineering to realize those rights. Global climate change has made the realization of the HRtWS more pressing and more difficult but newer international agreements including the Millennium Development Goals (MDGs) and current Sustainable Development Goals (SDGs) have helped keep attention on water and sanitation access.

Related to our current efforts to understand the scale and scope of this rapidly expanding literature, several scholars have emphasized the need to create greater synergy across the literature with a particular focus on the necessity of interdisciplinary engagement [37]. For instance, Obani and Gupta [38] highlight how legal scholars working on water and sanitation shoud more fully engage with non-legal literature and vice versa or the hydorlogists with the political scientists. Meanwhile, Feris [39] critiques the divergence in research related to the human right to sanitation and its lack of engagement with environmental considerations. We take these recommendations as the starting point for our project, which seeks to provide a clearer picture of the disparate literature on the human right to water and sanitation.

\section{Data and Methods}

\subsection{Data Collection Process}

To initiate our study, we needed to identify central repositories of academic research from which we could search for articles related to the human right to water and sanitation. To do so, we relied on two of the most prominent abstract and citation indexing databases: Scopus and the Web of Science Core Collections. These two databases are particularly valuable when compared to alternatives such as Google Scholar because of the latter's issues with replicability. In other words, scholars seeking to replicate our search process would generate an identical repository of articles when using Scopus and Web of Science for article aggregation while Google Scholar's indexing limits reproducibility. For instance, Gusenbauer and Haddaway [40] (p. 211) note that Google Scholar is "highly precise for exploratory searches ... (for) a user interested in only a few relevant results on the first search engine results page ... (but) precision has been found to be significantly lower than $1 \%$ for systematic searches." In short, our strategy is consistent with other systematic reviews and meta-analysis efforts [40,41].

To begin our search, we compiled a series of search strings related to the human right to water and sanitation. (The entire sample of search strings and search syntax can be found in Table S1 in our Supplementary Materials). For example, "human right to water," "constitutional right to water," and "right to sanitation" were key search strings. To ensure that our list of search strings was as complete and detailed as possible, we consulted with over a dozen researchers, practitioners, and subject-matter experts who offered additional terms to be included and/or recommended the removal of specific search strings. While impractical to include every search term, our list of search strings is quite comprehensive 
and as exhaustive as possible in an effort to ensure completeness. The results of our search led to a significant catalog of published research articles.

For instance, the Web of Science search yielded a total of 15,261 records while the Scopus search returned 19,083 records. The results of this exercise were then merged into a single record of abstracts for the period 1990-2020. Since both Web of Science and Scopus provide comprehensive indexing of academic research, we filtered and removed duplicate entries. This process entailed first removing those articles with identical titles and/or abstracts and then assessing the remaining records utilizing a series of matching procedures. First, we matched records according to similarities in titles. Second, we used a term-frequency inverse-document-frequency (TF-IDF) method that provides a cosine similarity score across article abstracts. Scores between 75 and 85 were manually reviewed, resulting in a cut-off threshold score of approximately 80 where all articles above this threshold were flagged as duplicates and subsequently removed. Following these steps, we were left with a total of 13,966 unique records.

The NLP method includes a variety of pre-processing steps before applying the unsupervised Latent Dirichlet Allocation (LDA) clustering method (discussed below). In addition to the removal of stop-words (and, to, the, but, etc.), and punctuation (, \.?",etc.) from the text, it must be reduced to its base form. We chose to lemmatize text to preserve its root meaning rather than stemming it, where its rhetorical usage can be obscured. Finally, given that the human right to water and sanitation contains a wide range of papers topically, some concerned with chemical or engineering facets, we reduced the dictionary to only nouns. This was an important step for two reasons. First, it created a smaller corpus that could be more easily modeled during our topic modeling strategy. Second, and more importantly, it allowed us to hone in on clustering the particular topics as they appear, rather than the particular rhetoric and writing style that is used across a range of scientific disciplines.

Once all unique records were pre-processed, we initiated the data analysis. This included descriptive publication patterns aimed to identify trends in the number of publications each year and the specific journals in which these publications were most likely to appear. Once exploratory analyses were complete, a topic model was performed. Topic modeling, more specifically Latent Dirichlet Allocation (LDA), is a text mining strategy used to identify topics across a set of text data or corpus [42]. This is an unsupervised machine learning approach to clustering. For this process, the researcher provides the algorithm with a parameter, number of topics, and it constructs the optimal set of vectors given the number of clusters and corpus. What this looks like in practice is a set of documents representing a corpus. Given this corpus and a set number of topics (for example 5), the LDA will group words (vectors) found across documents into 5 groups. Each document contains a given distribution summing to 1 of how much a particular cluster is represented within it. That is to say, once the number of topics is set at 5 , each topic (Topic 1 , Topic $2, \ldots$ Topic 5) is a set of word vectors. Given this set of words, a document has a distribution that is made up of the 5 clusters. Topic 1 might be 0.25 , Topic 20.25 , Topic 3 and Topic 4 are 0.0 , and Topic 5 is 0.5 . This means that Topic 5 is the most important topic for this particular document, followed equally by Topics 1 and 2 .

\section{Unpacking Trends in the Literature on the Human Right to Water and Sanitation}

In this section, we turn our attention to the trends identified from our empirical strategy. First, we consider both the temporal trends on the human right to water and sanitation and the most prevalent outlets for the field. Figure 1 provides a graphical depiction of the rate of publications since 1990 where the left $Y$-axis provides a count of the yearly sum of articles related to the HRtWS and the right $Y$-axis reports the cumulative total. Perhaps unsurprisingly, there has been a dramatic increase in the number of publications dealing with topics on the HRtWS since 1990 with noticeable upticks in several places. What is most interesting, from our perspective, is the sharp increase over the past decade. For instance, in 2010, the year the human right to water and sanitation was officially estab- 
lished by the United Nations General Assembly, the total number of annual publications approached 500. By 2020, that number more than tripled with nearly 1750 publications. While multiple factors contribute to an uptick in publications (i.e., the establishment of more journals) it is interesting to note the substantial increase in articles since these rights were officially codified.

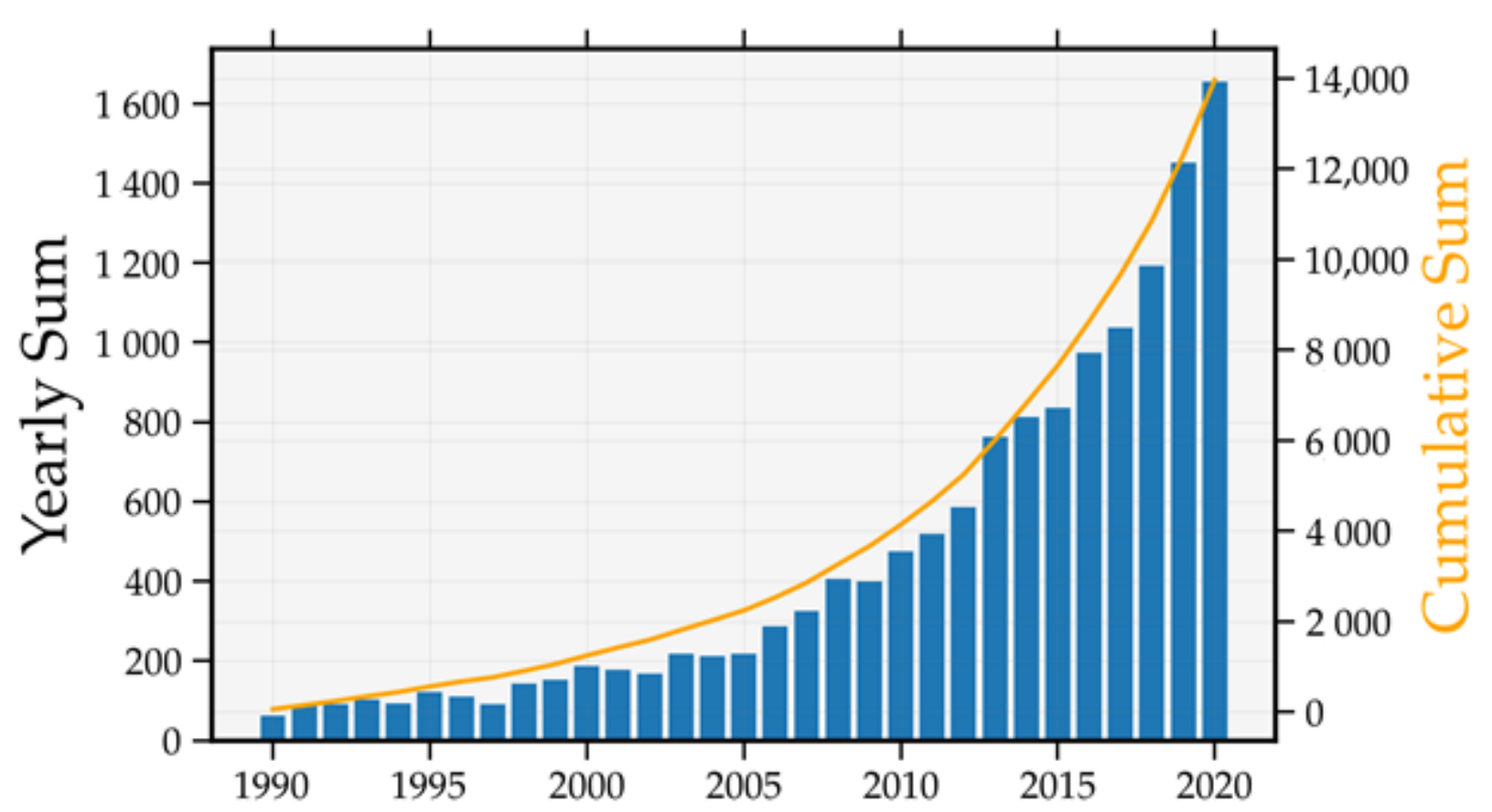

Figure 1. Annual number of papers published on the human right to water and sanitation. * Figures exclude records that lacked an abstract.

In addition to the general growth in the number of publications, it is worth commenting on the cumulative totals across each decade. Between 1990 and 1999 a total of 1059 articles were published related to the human right to water and/or sanitation, accounting for approximately $7.6 \%$ of all articles published during the temporal scope of our exploration. The number of articles more than doubled in the second decade (2000-2009), with 2605 publications or approximately $18.6 \%$ of all publications over the past thirty years. The final decade (2010-2020) saw the most significant growth, with 10,302 articles published, equating to nearly $74 \%$ of the overall corpus. We think it is important to note that our final decade (2010-2020) has a larger temporal scope (by one year) compared to the two previous decades. Regardless of where we ultimately delineate our cut-points (i.e., 1990-2000; 2001-2010; 2011-2020), the temporal trends are generally consistent.

\section{Main Journals}

While Figure 1 is instructive of the dramatic increase in the quantity of research, Figure 2 illustrates the outlets which publish most frequently on topics related to the human right to water and sanitation. It is important to note that the rankings here correspond to the frequency in which a journal publishes research that was identified using our list of search strings as discussed in Section 3.1. This exercise provides a first look at the types of outlets producing research on or related to the human right to water and sanitation and there are several noteworthy trends. First, the journal Water earns the unique distinction as the outlet that has published the most research related to the HRtWS. This journal was established in 2009 but has emerged as a front-runner in the production of scholarship on topics related to the HRtWS. Between 2009 and 2020, Water published over 350 articles on topics connected to the human right to water and sanitation, nearly double the number of articles published in the journal Water Policy which sits in the number two spot. In second place is Water Policy which was first established in 1998 and was absorbed by the 
International Water Association (IWA) in 2003. IWA houses several journals on this list in addition to Water Policy including, Water Science and Technology, the Journal of Water, Sanitation \& Hygiene for Development, and Water Research, which it supports in association with Elsevier.

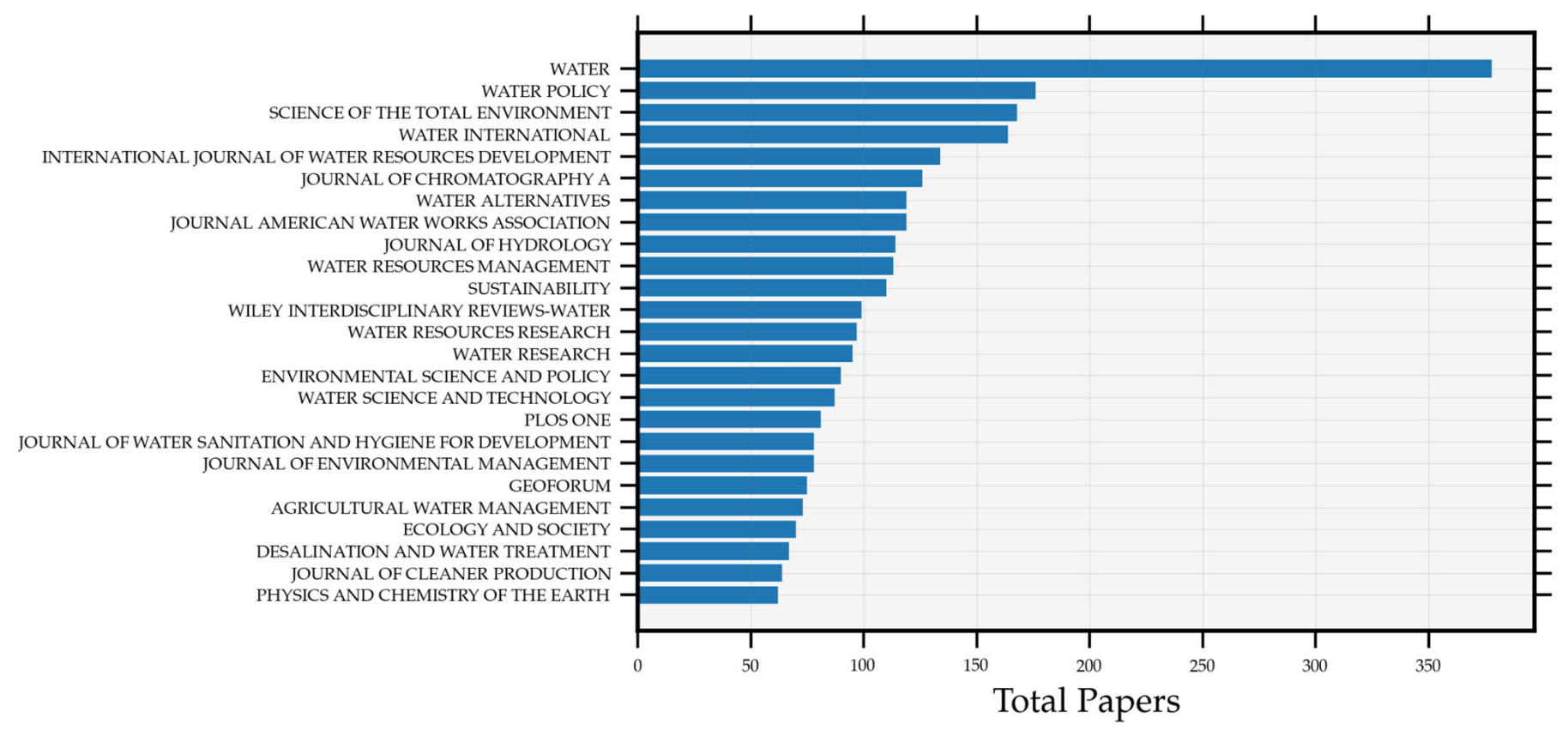

Figure 2. Number of papers published in the top 25 journals, 1990-2020. * It is worth pointing out that while this figure provides the list of the top 25 journals, the number of journals publishing research on/related to the HRtWS is quite large. For instance, in 2020 alone, over 770 different journals published at least one paper on topics related to the HRtWS.

Second, 11 journals have published at least 100 papers related to topics on the HRtWS. Such outlets include Sustainability, International Journal of Water Resource Development, and Water Alternatives-An Interdisciplinary Journal on Water Politics and Development. Third, an important feature of the list of the top 25 outlets is both the multidisciplinary nature of, and interdisciplinary approaches within, these journals. While scholars consistently refer to the study of the human right to water and sanitation as an increasingly multidisciplinary field, the list of outlets producing research on these topics provides a graphical representation of the truly multidisciplinary nature of the field and a cursory look at articles reveals the interdisciplinary approaches to addressing questions on the HRtWS. For instance, at first glance, the Journal of Hydrology may not appear as a relevant outlet for research related to the HRtWS, but recent publications include papers on water security in changing environments [43], drought reconstruction and water scarcity in India [44], governing water services in Europe [45], and water management issues in megacities [46], to name a few. Moreover, Wiley Interdisciplinary Reviews-Water illustrates scholarly efforts to pursue interdisciplinary approaches in the study of HRtWS, merging, for instance, the fields of sociology and water science [47].

\section{Topic Modeling}

As the trends above suggest, research on the human right to water and sanitation has grown dramatically over the past decade. Yet, simply identifying trends in publication counts and outlets only tells a partial story in our effort to synthesize broader trends in the literature. In this section, we examine the evolution of topics addressed in the literature over the past thirty years. 
In utilizing this topic modeling strategy, it was incumbent on the authors to assign topic labels based upon the topic ranking and relevance scores. As noted, each topic is comprised as a series of most relevant terms where the total of each series of terms equals 1 . For example, Topic 16 includes terms such as water, security, resource, supply, etc., which led us to label it "water security and supply." To arrive at such a conclusion for our most important topics (i.e., identified in Figure 3), we adopted an iterative process where each author assessed topics independently, arriving at an independently designated topic label. Through consultation, the authors then determined an agreed-upon topic label that most closely reflected the labels each author generated independently. For instance, Topic 19 included terms such as climate, water, climate change, rainfall, and impact. The authors independently arrived at topics such as climate and water, climate change and water, and water and climatic factors. Given the overlap in topic designations, the authors then agreed upon "climatic factors and water" as the topic label for Topic 19. From our perspective, it is important to note that labeling topics necessitates some degree of subjectivity on the part of the labelers. As we discuss, our labeling strategy was consultative but a different group of researchers may arrive at different topic labels based on the terms which appear under each topic. As a result, and for transparency, we have included the full list of 31 topics including the top 15 terms under each topic in Table S2 in our Supplementary Materials.

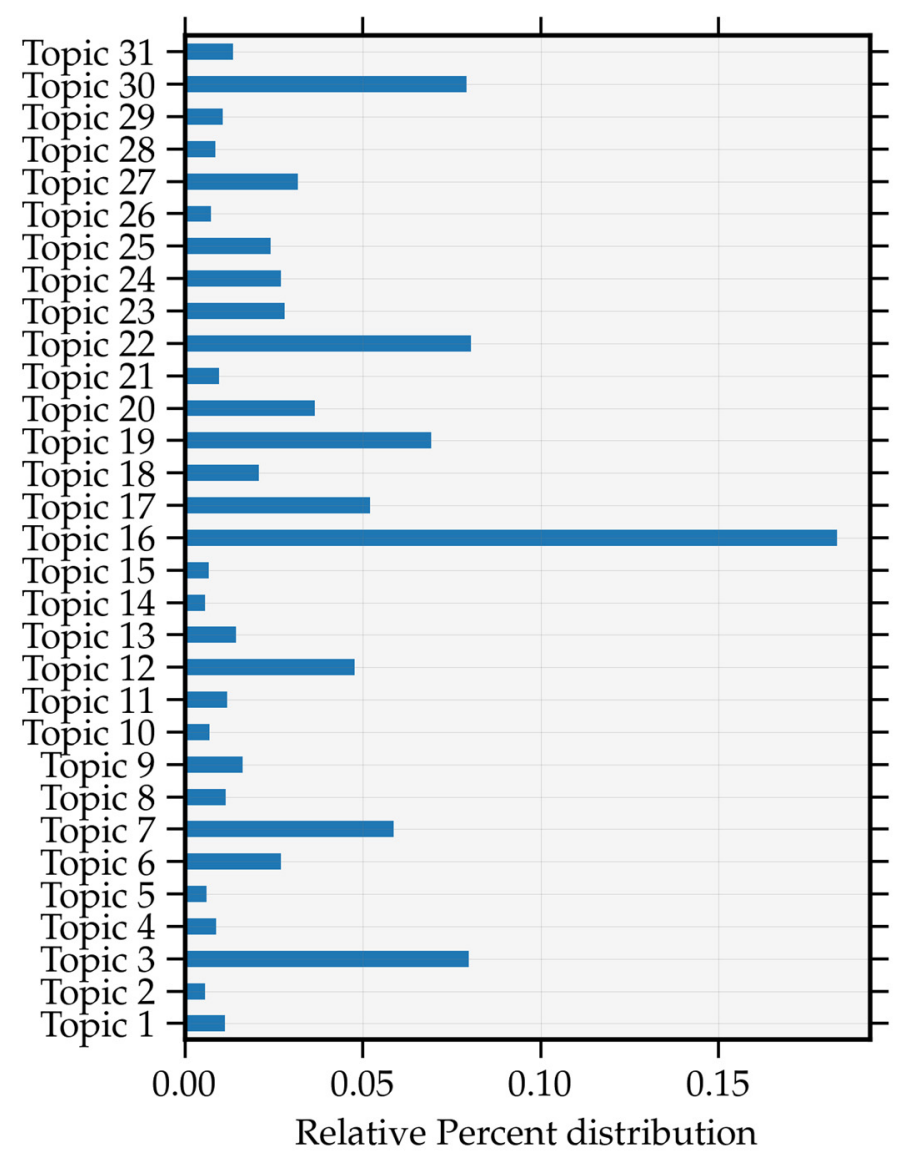

Figure 3. Distribution of topics across publications, 1990-2020.

Figure 3 plots the relative distribution of topics across all publications from 1990 to 2020. A few major themes emerge. First, Topic 16 vividly stands out as the most frequently published across all journals. Topic 16 broadly focuses on issues related to water security and supply, key aspects of the human right to water and sanitation. Topic 3-Water Research, Governance, and Development, Topic 19-Climatic Factors and Water, Topic 22-Water Policy and Management, and Topic 30-Water Quality and Treatment round out the top five topics identified via our topic modeling strategy. Other topics that appear 
to be quite salient in the research on the human right to water and sanitation include Topic 7-Science and Water, Topic 12-Water Governance and Resilience, Topic 17-Water and Health, and Topic 20-Water and Agriculture.

In Figure 4, we plot the top five topics temporally, illustrating the frequency in which each topic appears in publications over the period 1990-2020. The X-axis shows the temporal scope of our study (1990-2020), while the $Y$-axis shows the average topic importance at the yearly level essentially depicting the relative importance of the cluster of words that account for each designated topic across all publications in each respective year. Moving from left to right across the graph, we can see how the average importance of each topic changes over time.

\section{Top Topics}

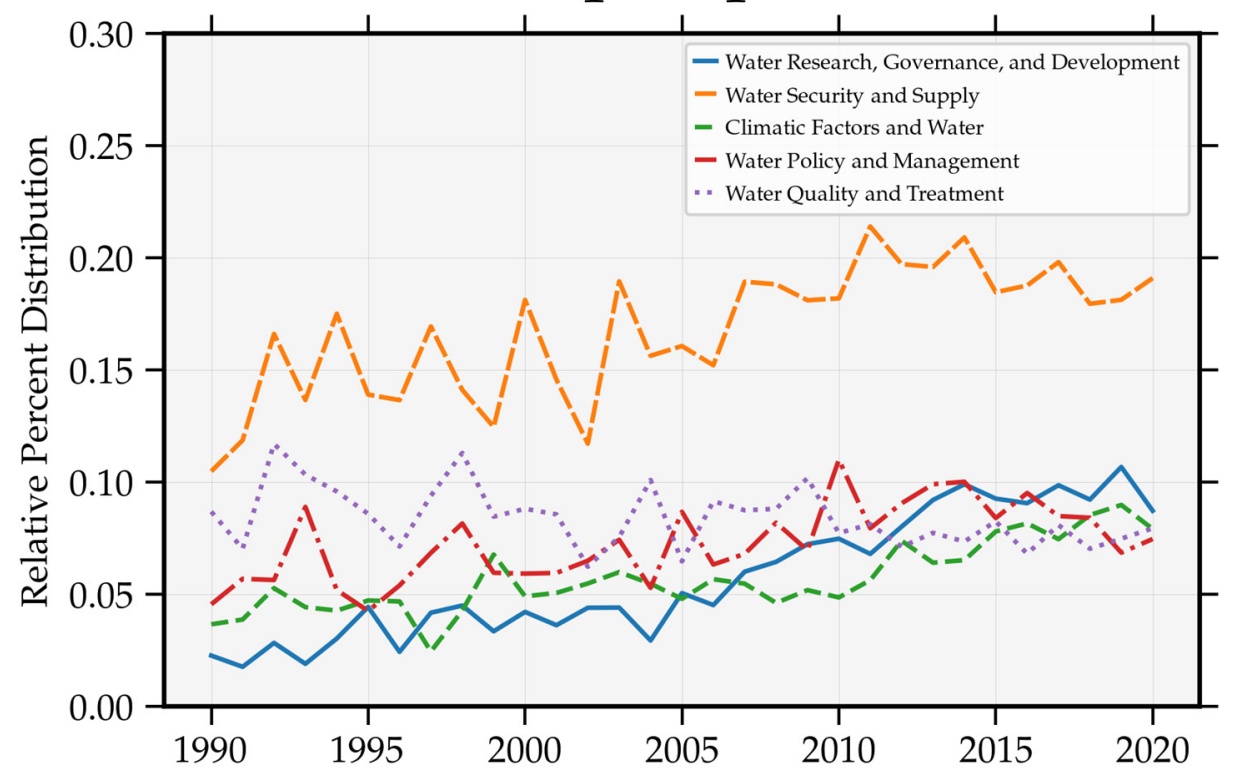

Figure 4. Top 5 topics—trends over time, 1990-2020.

With the exception of Topic 30-Water Quality and Treatment, which has remained relatively constant over time, there appears to be a general increase in average importance across each of the main topics since 1990. While part of these upward trends may be explained by general increases in the number of outlets and/or publication processes that allow for more frequent publishing, the patterns also suggest that scholars may be devoting increased attention to certain topics. For instance, in 1990, Topic 3-Water Research, Governance, and Development was the least important topic of the 5 depicted in Figure 4. By 2020, water research, governance, and development sat only behind Topic 16-Water Security and Supply as the most frequently published topic. The most significant spike appears to have taken place after 2010 which aligns with the UN's formal recognition of the human right to water and sanitation. For Topic 16-Water Security and Supply, the sharp dip in the early 2000s appears to have rebounded considerably post-2002, perhaps the result of increased attention on the HRtWS ushered in by General Comment 15. Meanwhile, Topic 19-Climatic Factors and Water spiked in the late 1990s after a sharp decline in approximately 1996 and has seen steady growth since 2000. While we are cautious to discuss causality as our empirical strategy can only offer descriptive insights, there are some interesting parallels to consider. For instance, the 2002 initial quasi-recognition of right to water via General Comment 15, the 2010 codification of the HRtWS, and the expiration of the Millennium Development Goals (MDGs) in 2015 (for details on the MDGs, see https:/ / www.un.org/millenniumgoals/bkgd.shtml) (accessed on 17 October 2021) and establishment of the Sustainable Development Goals (SDGs) might help us understand the growth of research on climatic factors and water (for more information on the SDGs, 
see https://www.un.org/sustainabledevelopment/) (accessed on 17 October 2021). SDG 6 and SDG 13 for example, center on access to clean water and sanitation and climate action, respectively. There has also been increasing awareness of environmental issues compounding water access issues (climate change; urbanization, etc.,) as well as research on judicial decisions on the legal rights of rivers [48].

One final interesting observation is a slight decline in research on Topic 22-Water Policy and Management since the period 2015-2016. Part of this decline may potentially be explained by a shift to research focusing on climatic factors and water as well as the increasing attention given to Topic 3-Water Research, Governance, and Development. In this latter case, the divergent paths of Topic 22-Water Policy and Management and Topic 3-Water Research, Governance, and Development since 2015 are interesting as more scholarly attention appears to have focused on issues of water governance and development in place of management and policy issues. From our perspective, such topics largely intersect and this appears to be reflected in the near convergence between these topics in 2020.

\section{Main Topics across Journals}

Shifting away from general topical trends across all journals, Figure 5 plots the salience of topics across the top four most active journals that have published research related to the human right to water and sanitation over the past thirty years. Beginning with the top left quadrant, Water International publishes frequently across Topics 16-Water Security and Supply, 22-Climatic Factors and Water, and 3-Water Research and Development. Recent research across these topics include projects on desalination to address issues of water (in)security in Jordan [49], the use of computational text and data mining tools to understand water disputes in Chile [6], and rainwater harvesting as a means for household security in Uganda [50].

Meanwhile, Water Policy (top right quadrant) has more heavily published articles related to Topic 16-Water Security and Supply such as papers on water privatization and consumption in urban centers of Ghana [51], regional water security issues in China [52], and transboundary water conflicts in river basins [53]. However, it also frequently publishes papers related to Topic 22-Climatic Factors and Water including, for example, research on drought management and water governance in South Africa [54], climate readiness for the provision of water services in Sydney [55], and climate change implications for Sao Paulo [56].

Prevalent topics in the journal Science of the Total Environment (bottom left quadrant) include articles related to Topic 16-Water Security and Supply, Topic 19-Climatic Factors and Water, and Topic 30-Water Policy and Management. Recent examples that intersect some of these topics include water-related challenges for governance and sustainable development in Peru [57], issues of urbanization and water security [58], regional threats to human water security in South Korea [59], and freshwater vulnerability and climate change across Europe [60].

Lastly, the journal Water (bottom left quadrant) publishes most frequently on Topics 16-Water Security and Supply and 3-Water Research, Governance, and Development. Recent publications include topics on water scarcity and inefficient water usage in the United States [61], the effects of constitutionalizing the human right to water [27], water governance and policy in India [62], water security challenges in Togo [63]. Across each of the top four journals, the multidisciplinary nature of topics is quite apparent which speaks to the importance of engagement with a wide selection of academic outlets. 
WATER INTERNATIONAL
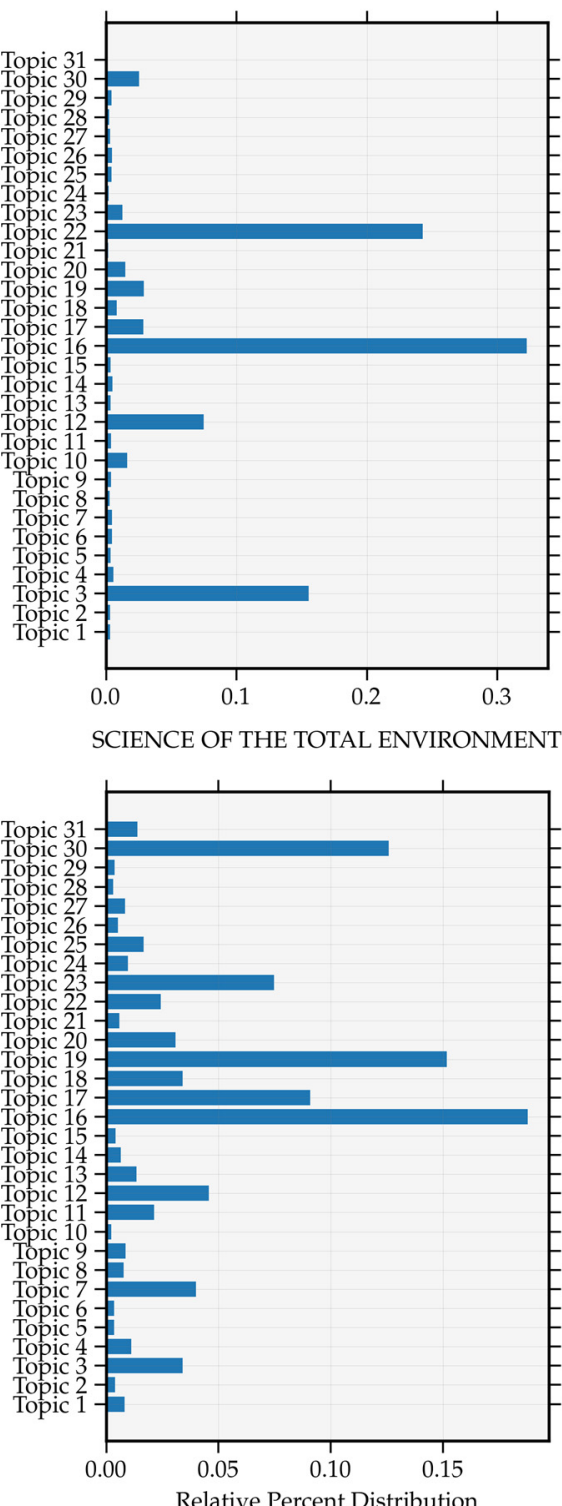

WATER POLICY
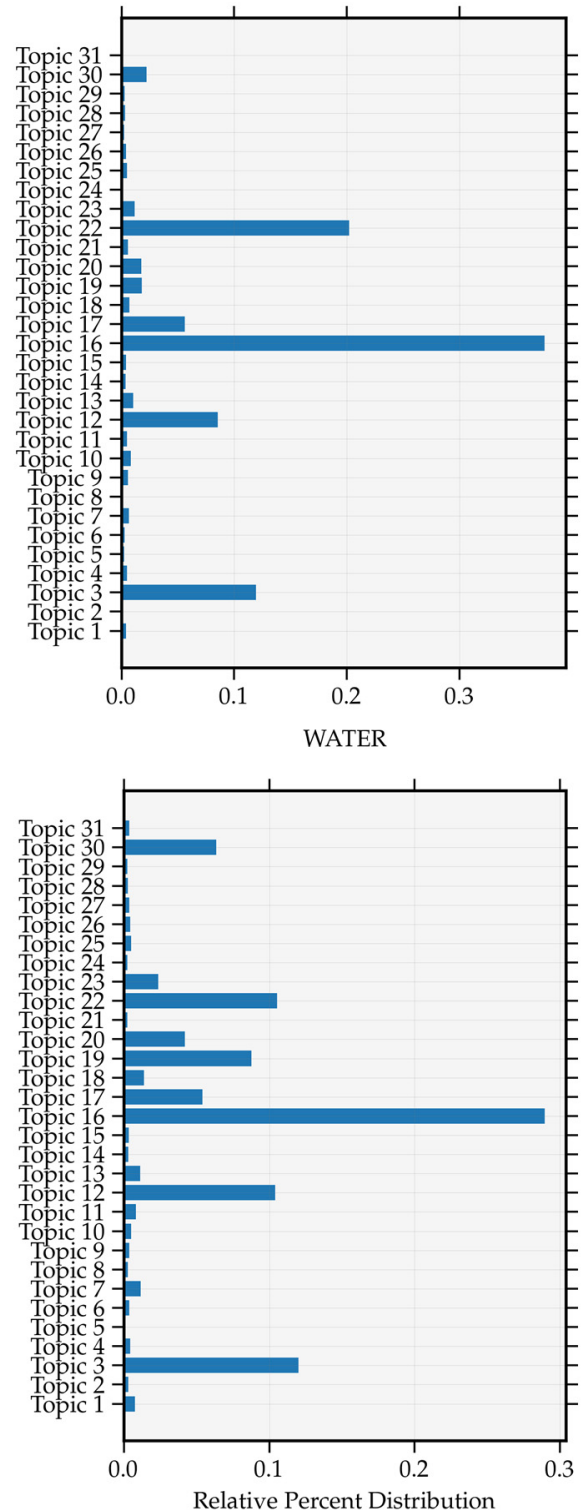

Figure 5. Topic salience across top four journals, 1990-2020.

\section{Discussion and Implications}

Leveraging advances in natural language process and machine learning, this paper applied a systematic approach to explore the evolution and topical trends in the academic literature on the human rights to water and sanitation over the past three decades. To the best of our knowledge, this effort represents one of the first and most extensive attempts to map and synthesize this rapidly expanding literature.

While our study is narrowly focused on the human right to water and sanitation, it is illustrative of the power such methodological strategies can have for the broader field of human rights. Our approach to examining the evolution of topics in the literature on the human rights to water and sanitation provides scholars and practitioners alike with a valuable tool in assessing trends in academic scholarship and specifically highlights emerging areas of research. There are at least four important takeaways from our study. First, our topic modeling approach has revealed how the academic literature on the HRtWS has evolved over the last three decades [64]. While the exponential growth in the number of peer-reviewed publications is of course an important finding, the topic modeling illustrates where this discourse has largely focused. For instance, while Topic 16-Water Security and 
Supply holds the top spot, other topics such as Topic 19-Climatic Factors and Water have seen a steady influx of academic publications since 2010. This is perhaps unsurprising given the increasing importance of climate change as a threat to water access and security and it is a reasonable expectation that such research will continue to increase in frequency. This raises an additional element for consideration: within our topical designations, there are likely several intersectional topics worth further consideration. For example, there may be close linkages to climatic factors and water security/supply that our topic modeling approach could not fully account for. Still, our study offers a strong first attempt to unpack the complexities of the research on the HRtWS.

Secondly, such trends also reveal areas that may need more attention. For instance, Topic 10-Water and Conflict, while salient, appears to be investigated and published on less frequently than many other topics. From our perspective, and given the frequency and attention to which scholars have devoted to Topic 16-Water Security and Supply, Topic 19-Climatic Factors, and Topic 3-Water Research, Governance, and Development, there is potential for much more research to be done on water and conflict. Similarly, while Topic 17-Water and Health is a salient topic in the literature, one might expect more research to emerge given both the centrality of safe water and sanitation to beneficial health outcomes [65] and the increased attention on global health during the ongoing COVID-19 pandemic.

Third, many topics appear to focus more directly on the human right to water, issues of water security, and challenges of water management policy, and governance. This is not to say that sanitation is unimportant, but it does appear that research and publications on the human right to sanitation have been relegated to a somewhat secondary area in terms of topical importance across assessed publications. Schiel et al. [27], for instance, identify this shortcoming and some of the underlying difficulties in researching topics related to sanitation. For our study, this is most directly reflected in the fact that the word sanitation only appears once in the list of top words in our topic modeling approach. Specifically, it falls under Topic 17-Water and Health. This is not surprising given the clear intersections between sanitation and health, but it is perplexing why topics that specifically focus on sanitation are not more apparent across our empirical assessment. Still, it is worth noting that scholars have devoted significant attention to sanitation and indeed, several indices have emerged that emphasize the importance of considering issues related to sustainability for the integrity of sanitation systems [66,67]. We believe this line of inquire is important given the intersection between sustainability and the HRtWS. Our investigation might be fruitful for helping scholars think through topics that may be important in the construction of indices more oriented to human rights.

Fourth, and as we specified several times, the list of top 25 journals in terms of frequency of production of research related to the HRtWS is interesting as it reveals the multidisciplinary nature of the human right to water and sanitation as well as the interdisciplinary approaches used by scholars investigating questions related to these rights. This is likely unsurprising to those who work in this field, but does suggest a need for researchers to be familiar with a wide range of scholarship outside of their own discipline and to consider opportunities to develop multidisciplinary skills or collaborate on multidisciplinary teams.

While some bias exists when relying on a corpus of peer-reviewed research, our efforts provide an important foundation for synthesizing the state of academic research on the human right to water and sanitation. Still, a few limitations are worth mentioning here. First, as we note, topic modeling is a useful strategy for unpacking general trends via NLP but requires users to label respective topical categories. In other words, there is not an objective process for doing so. While we sought to label topics based on consultative procedure, different researchers may arrive at different topic labels. We do not see this as much of an issue for understanding trends in the literature, but rather suggest that those interested in our study heed this point and consider the ensemble of words within each topic. Second, our empirical strategy unfortunately was unable to account for NGO, 
$\mathrm{UN}$, and other non-peer-reviewed publications that may address issues, progress, and/or challenges related to the human right to water and sanitation. While our study is clearly centered on unpacking trends in academic work it is worth noting that work on human rights - and specifically the rights to water and sanitation - has been widely written about in these non-peer-reviewed outlets. While there may be similarities across academic and non-academic writing, future research might consider ways to expand the scope of our efforts though it is important to consider that a central difficulty in conducting such a study is the ability to identify a clear corpus from which to draw articles, reports, etc.

While our empirical strategy is telling and provides a useful starting point via the uncovering of patterns across the corpus of peer-reviewed research from 1990 to 2020, our topic modeling approach is unable to engage with the theoretical substance of the research. In other words, we are able to offer a synthesized look at the literature over the past thirty years, but researchers will need to take the next steps to more fully understand the practical and theoretical implications of identified patterns. Overall, we believe this project provides an important baseline for unpacking three decades worth of peer-reviewed research on the human right to water and sanitation. The growth of the field in terms of sheer quantity is encouraging as it suggests a growing interest and willingness of researchers to pursue projects on these newly established rights as well as increasing interest from academic journals. While such growth is not entirely driven by the UN's adoption of these rights in 2010 (i.e., the number of journals has increased), there is reason to suspect that the establishment of these rights has been at least somewhat influential. Overall, we believe this study serves as a useful foundation in efforts to learn where academic research on the HRtWS has concentrated and the direction of its future trajectory.

Supplementary Materials: The following are available online at https:/ / www.mdpi.com/article/10 .3390/w13243501/s1, Table S1: Search strings for Web of Science and Scopus, Table S2: Top 15 terms by topic, 1990-2020.

Author Contributions: Conceptualization, C.M.F., J.E.L. and B.M.W.; methodology, J.E.L. and C.M.F.; software, J.E.L.; validation, J.E.L. and C.M.F.; formal analysis, J.E.L.; investigation, C.M.F., J.E.L., M.S.F. and B.M.W.; resources, B.M.W. and M.S.F.; data curation, C.M.F., J.E.L. and M.S.F.; writingoriginal draft preparation, C.M.F., J.E.L., B.M.W. and M.S.F.; writing-review and editing, C.M.F., J.E.L., B.M.W. and M.S.F.; visualization, J.E.L.; supervision, B.M.W.; project administration, B.M.W. and C.M.F.; funding acquisition, B.M.W. All authors have read and agreed to the published version of the manuscript.

Funding: Research funded by the Norwegian Research Council. "Elevating Water Rights to Human Rights: Has it strengthened marginalized peoples' claim for water? (Forskerprosjekt-FRIHUMSAM project number 263096). P.I. Bruce M. Wilson and the University of Central Florida Preeminent Postdoctoral Program (P3) grant number 0000007509; P.I. Bruce M. Wilson.

Institutional Review Board Statement: Not applicable.

Informed Consent Statement: Not applicable.

Data Availability Statement: The data presented and analyzed in this study can be replicated by following the procedures outlined and reviewing the Supplementary Materials.

Acknowledgments: The authors would like to thank Kerstin Hamann for insightful, helpful suggestions on an earlier version of this manuscript.

Conflicts of Interest: No conflict of interest. Disclaimer from Christopher M. Faulkner: The views expressed in this manuscript do not represent the Naval War College, Department of the Navy, or the U.S. Government.

\section{References}

1. Hirschberg, J.; Manning, C.D. Advances in natural language processing. Science 2015, 349, 261-266. [CrossRef]

2. Edgcomb, J.B.; Zima, B. Machine learning, natural language processing, and the electronic health record: Innovations in mental health services research. Psychiatr. Serv. 2019, 70, 346-349. [CrossRef] [PubMed] 
3. Fisher, I.E.; Margaret, R.G.; Mark, E.H. Natural language processing in accounting, auditing and finance: A synthesis of the literature with a roadmap for future research. Intell. Syst. Account. Financ. Manag. 2016, 23, 157-214. [CrossRef]

4. Medvedeva, M.; Vols, M.; Wieling, M. Using machine learning to predict decisions of the European Court of Human Rights. Artif. Intell. Law 2020, 28, 237-266. [CrossRef]

5. Park, B.; Greene, K.; Colaresi, M. Human rights are (increasingly) plural: Learning the changing taxonomy of human rights from large-scale text reveals information effects. Am. Political Sci. Rev. 2020, 114, 888-910. [CrossRef]

6. Herrera, M.; Candia, C.; Rivera, D.; Aitken, D.; Brieba, D.; Boettiger, C.; Donoso, G.; Godoy-Faúndez, A. Understanding water disputes in Chile with text and data mining tools. Water Int. 2019, 44, 302-320. [CrossRef]

7. United Nations. The Human Right to Water and Sanitation-Resolution No. 64/292. In Proceedings of the United Nations General Assembly, New York, NY, USA, 28 July 2010; A/RES/64/292. Available online: https://www.un.org/en/ga/search/ view_doc.asp?symbol=A/RES/64/292 (accessed on 10 October 2021).

8. CESCR-Committee on Economic, Social and Cultural Rights General Comment no. 15. United Nations. 2002. Available online: https:/ / digitallibrary.un.org/record/486454?ln=en (accessed on 11 October 2021).

9. UN Committee on Economic, Social and Cultural Rights. General Comment No. 15: The Right to Water; U.N. Doc. E/C.12/2002/11. Available online: https:/ / documents-dds-ny (accessed on 31 July 2021).

10. Meier, B.M.; Kayser, G.L.; Amjad, U.Q.; Bartram, J. Implementing an evolving human right through water and sanitation policy. Water Policy 2013, 15, 116-133. [CrossRef] [PubMed]

11. Langford, M.; Russell, A.F.S. The right to water in context. In The Human Right to Water: Theory, Practice and Prospects, 1st ed.; Langford, M., Russell, A.F.S., Eds.; Cambridge University Press: Cambridge, UK, 2017; pp. 1-55. ISBN 978-0-511-86260-1.

12. McCaffrey, S.C. A human right to water: Domestic and international implications. Georget. Int. Environ. Law Rev. 1992, 5, 1-24.

13. Gleick, P.H. The Human Right to Water. Water Policy 1999, 5, 487-503. Available online: https://pacinst.org/wp-content/ uploads/2012/10/basic_water_needs_human_right_to_water.pdf (accessed on 15 September 2021).

14. GBD 2017 Risk Factor Collaborators. Global, regional, and national comparative risk assessment of 84 behavioural, environmental and occupational, and metabolic risks or clusters of risks for 195 countries and territories, 1990-2017: A systematic analysis for the Global Burden of Disease Study 2017. Lancet Glob. Health Metr. 2018, 392, 1923-1994.

15. Jolly, R. Water and human rights: Challenges for the 21st century. In Proceedings of the Conference of the Belgian Royal Academy of Overseas Sciences, Brussels, Belgium, 23 March 1998; quoted in Gleick 1999, Volume 3.

16. Prasad, N. Privatisation of water: A historical perspective. Law Environ. Dev. J. 2007, 3, 217. [CrossRef]

17. Baer, M. Stemming the Tide: Human Rights and Water Policy in a Neoliberal World; Oxford University Press: Oxford, UK, 2017; ISBN 978-0-190-69315-2.

18. Finnegan, W. Leasing the Rain. The New Yorker, 8 April 2002. Available online: https://www.newyorker.com/magazine/2002/0 4/08/leasing-the-rain (accessed on 10 September 2021).

19. Bluemel, E. The implications of formulating a human right to water. Ecol. LQ 2004, 31, 957.

20. Murphy, S.L. The human right(s) to water and sanitation: History, meaning, and the controversy over-privatization. Berkeley J. Int. Law. 2013, 31, 89-147.

21. Singh, N. Translating human right to water and sanitation into reality: A practical framework for analysis. Water Policy 2013, 15, 943-960. [CrossRef]

22. Salman, S.M. The human right to water and sanitation: Is the obligation deliverable? Water Int. 2014, 39, 969-982. [CrossRef]

23. Baer, M.; Gerlak, A. Implementing the human right to water and sanitation: A study of global and local discourses. Third World Q. 2015, 36, 1527-1545. [CrossRef]

24. Posner, E.A. The Twilight of Human Rights Law; Oxford University Press: Oxford, UK, 2014; ISBN 978-0-199-31344-0.

25. Sikkink, K. Evidence for Hope; Princeton University Press: Oxford, UK, 2017; ISBN 978-0-691-17062-6.

26. Koff, H.; Maganda, C. The EU and the human right to water and sanitation: Normative coherence as the key to transformative development. Eur. J. Dev. Res. 2016, 28, 91-110. [CrossRef]

27. Schiel, R.; Wilson, B.M.; Langford, M. The determinants of access to sanitation: The role of human rights and the challenges of measurement. Water 2021, 13, 1676. [CrossRef]

28. Campbell, O.M.; Benova, L.; Gon, G.; Afsana, K.; Cumming, O. Getting the basic rights-The role of water, sanitation and hygiene in maternal and reproductive health: A conceptual framework. Trop. Med. Int. Health 2015, 20, 252-267. [CrossRef]

29. Breen, M.; Gillanders, R. Money down the Drain: Corruption and Access to Water in Sub-Saharan Africa. 2021. Available online: https:/ / ssrn.com/abstract=3866657 (accessed on 17 October 2021).

30. Tezcur, G.; Schiel, R.; Wilson, B.M. The effectiveness of harnessing human rights: The struggle over the Ilısu Dam in Turkey. Dev. Chang. 2021, 52, 1343-1369. [CrossRef]

31. Viaene, L. Indigenous Water Ontologies, Hydro-Development and the Human/More-Than-Human Right to Water: A Call for Critical Engagement with Plurilegal Water Realities. Water 2021, 13, 1660. [CrossRef]

32. Del Carmen Morales, M.; Harris, L.; Ãberg, G. Citizenshit: The right to flush and the urban sanitation imaginary. Environ. Plan. A 2014, 46, 2816-2833. [CrossRef]

33. Ranganathan, M. Paying for pipes, claiming citizenship: Political agency and water reforms at the urban periphery. Int. J. Urban Reg. Res. 2014, 38, 590-608. [CrossRef] 
34. Ly, K.; Metternicht, G.; Marshall, L. Transboundary river basins: Scenarios of hydropower development and operation under extreme climate conditions. Sci. Total Environ. 2022, 803, 149828. [CrossRef]

35. Esculier, F.; Le Noë, J.; Barles, S.; Billen, G.; Créno, B.; Garnier, J.; Lesavre, J.; Petit, L.; Tabuchi, J.-P. The biogeochemical imprint of human metabolism in Paris megacity: A regionalized analysis of a water-agro-food system. J. Hydrol. 2019, 573, 1028-1045. [CrossRef]

36. Schiel, R.; Langford, M.; Wilson, B.M. Does it matter? Rights, constitutionalisation, democratic governance, and the human right to water. Water 2020, 12, 350. [CrossRef]

37. Fantini, E. An introduction to the human right to water: Law, politics, and beyond. Wiley Interdiscip. Rev. Water 2020, 7, e1405. [CrossRef]

38. Obani, P.; Gupta, J. Human right to sanitation in the legal and non-legal literature: The need for greater synergy. Wiley Interdiscip. Rev. Water 2016, 3, 678-691. [CrossRef]

39. Feris, L. The human right to sanitation: A critique on the absence of environmental considerations. Rev. Eur. Comp. Int. Environ. Law 2015, 24, 16-26. [CrossRef]

40. Gusenbauer, M.; Haddaway, N.R. Which academic search systems are suitable for systematic reviews or meta-analyses? Evaluating retrieval qualities of Google Scholar, PubMed, and 26 other resources. Res. Synth. Methods 2020, 11, $181-217$. [CrossRef]

41. Lambert, J.; Epstein, G.; Joel, J.; Baggio, J. Identifying topics and trends in the study of common-pool resources using natural language processing. Int. J. Commons 2021, 15, 206-217. [CrossRef]

42. Blei, D.M.; Ng, A.Y.; Jordan, M.I. Latent dirichlet allocation. J. Mach. Learn. Res. 2003, 3, 993-1022.

43. Shao, M.; Zhao, G.; Kao, S.C.; Cuo, L.; Rankin, C.; Gao, H. Quantifying the effects of urbanization on floods in a changing environment to promote water security-A case study of two adjacent basins in Texas. J. Hydrol. 2020, 589, 125154. [CrossRef]

44. Mishra, V. Long-term (1870-2018) drought reconstruction in context of surface water security in India. J. Hydrol. 2020, 580, 124228. [CrossRef]

45. Renou, Y.; Bolognesi, T. Governing urban water services in Europe: Towards sustainable synchronous regimes. J. Hydrol. 2019, 573, 994-1006. [CrossRef]

46. Van den Brandeler, F.; Gupta, J.; Hordijk, M. Megacities and rivers: Scalar mismatches between urban water management and river basin management. J. Hydrol. 2019, 573, 1067-1074. [CrossRef]

47. Tipaldo, G.; Allamano, P. Citizen science and community-based rain monitoring initiatives: An interdisciplinary approach across sociology and water science. Wiley Interdiscip. Rev. Water 2017, 4, e1200. [CrossRef]

48. O'Donnell, E.L.; Talbot-Jones, J. Creating legal rights for rivers. Ecol. Soc. 2018, 23, 7. [CrossRef]

49. Walschot, M.; Luis, P.; Liégeois, M. The challenges of reverse osmosis desalination: Solutions in Jordan. Water Int. 2020, 45, 112-124. [CrossRef]

50. Staddon, C.; Rogers, J.; Warriner, C.; Ward, S.; Powell, W. Why doesn't every family practice rainwater harvesting? Factors that affect the decision to adopt rainwater harvesting as a household water security strategy in central Uganda. Water Int. 2018, 43, 1114-1135. [CrossRef]

51. Twum, K.O.; Abubakari, M. Drops in the city: The puzzle of water privatization and consumption deficiencies in urban Ghana. Water Policy 2020, 22, 417-434. [CrossRef]

52. Liu, H.; Jia, Y.; Niu, C.; Gan, Y.; Xu, F. Evaluation of regional water security in China based on dualistic water cycle theory. Water Policy 2018, 20, 510-529. [CrossRef]

53. Tian, G.L.; Liu, J.N.; Li, X.Y.; Li, Y.Q.; Yin, H. Water rights trading: A new approach to dealing with trans-boundary water conflicts in river basins. Water Policy 2020, 22, 133-152. [CrossRef]

54. Makaya, E.; Rohse, M.; Day, R.; Vogel, C.; Mehta, L.; McEwen, L.; Rangecroft, S.; Van Loon, A.F. Water governance challenges in rural South Africa: Exploring institutional coordination in drought management. Water Policy 2020, 22, 519-540. [CrossRef]

55. Chong, J. Climate-readiness, competition and sustainmability: An analysis of the legal and regulatory frameworks for providing water services in Sydney. Water Policy 2014, 16, 1-18. [CrossRef]

56. Braga, B.; Kelman, J. Facing the challenge of extreme climate: The case of metropolitan São Paulo. Water Policy 2016, 18, 52-69. [CrossRef]

57. Salmoral, G.; Zegarra, E.; Vázquez-Rowe, I.; González, F.; Del Castillo, L.; Saravia, G.R.; Graves, A.; Rey, D.; Knox, J.W. Waterrelated challenges in nexus governance for sustainable development: Insights from the city of Arequipa, Peru. Sci. Total Environ. 2020, 747, 141114. [CrossRef] [PubMed]

58. Kookana, R.S.; Drechsel, P.; Jamwal, P.; Vanderzalm, J. Urbanisation and emerging economies: Issues and potential solutions for water and food security. Sci. Total Environ. 2020, 732, 139057. [CrossRef] [PubMed]

59. Kim, Y.; Kong, I.; Park, H.; Kim, H.J.; Kim, I.J.; Um, M.J.; Green, P.A.; Vörösmarty, C.J. Assessment of regional threats to human water security adopting the global framework: A case study in South Korea. Sci. Total Environ. 2018, 637, 1413-1422. [CrossRef]

60. Koutroulis, A.G.; Papadimitriou, L.V.; Grillakis, M.G.; Tsanis, I.K.; Wyser, K.; Betts, R.A. Freshwater vulnerability under high end climate change. A pan-European assessment. Sci. Total Environ. 2018, 613, 271-286. [CrossRef] [PubMed]

61. Kehl, J. Moving beyond the mirage: Water scarcity and agricultural use inefficiency in USA. Water 2020, 12, 2290. [CrossRef]

62. Ahmed, M.; Araral, E. Water governance in india: Evidence on water law, policy, and administration from eight Indian states. Water 2019, 11, 2071. [CrossRef] 
63. Yomo, M.; Mourad, K.A.; Gnazou, M.D. Examining water security in the challenging environment in Togo, West Africa. Water 2019, 11, 231. [CrossRef]

64. Mirosa, O.; Harris, L. Human right to water: Contemporary challenges and contours of a global debate. Antipode 2012, 44, 932-949. [CrossRef]

65. Ray, I.; Smith, R.K. Towards safe drinking water and clean cooking for all. Lancet Glob. Health 2021, 9, e361-e365. [CrossRef]

66. Lundin, M.; Sverker, M.; Morrison, G.M. A set of indicators for the assessment of temporal variations in the sustainability of sanitary systems. Water Sci. Technol. 1999, 39, 235-242. [CrossRef]

67. Hashemi, S. Sanitation sustainability index: A pilot approach to develop a community-based indicator for evaluating sustainability of sanitation systems. Sustainability 2020, 12, 6937. [CrossRef] 